\title{
Research on the Parallelism Detection Between Nozzle and Floating Plate
}

\author{
HuangBin* \\ Institution of Instrument Science and Opto-electronics \\ Engineering \\ Hefei University of Technology \\ Hefei, China \\ e-mail: ahhb7310168@163.com \\ * Corresponding Author \\ LiChengwei \\ Institution of Instrument Science and Opto-electronics \\ Engineering \\ Hefei University of Technology \\ Hefei, China \\ e-mail: 836277034@qq.com \\ YiJiajing \\ Institution of Instrument Science and Opto-electronics \\ Engineering \\ Hefei University of Technology \\ Hefei, China \\ e-mail: a138tp@163.com
}

\begin{abstract}
In the air-floating six-axis force measurement platform, parallelism between the nozzle and the floating plate directly affects the machine's accuracy. For some reason about the structure of the flotation six-dimensional force measurement platform, we cannot use the conventional method to test on the parallelism between the nozzle and floating plate. This paper analyzes that how the parallelism between the nozzle and the floating plate affect the accuracy of flotation force measurement platform. Based on that we proposed a method of using indentation principle and equalthickness gasket principle to detect the parallelism between the nozzle and floating plate, and experiments proved the effectiveness of the proposed method, solving the problem of parallelism detection between the nozzle and the floating plate in the process of installing and commissioning the flotation six-dimensional force measurement platform.
\end{abstract}

Keywords-flotation-type; nozzle; parallelism; equalthickness gasket; indentation

\section{INTRODUCTION}

Six-axis force measuring method and six-axis force sensor have become a hot research topic in the field of multidimensional force measurement in recent years[1-3]. The precision of the six-axis force measurement is restricted by the coupling phenomenon. Decoupling algorithms have been investigated by many scientists [4-5] However, coupling is a complicated nonlinear problem and decoupling can never eliminate the measurement errors caused by coupling[6]. Therefore, six-axis force measuring methods without coupling are undoubtedly an

\author{
WangXiaomeng \\ Institution of Instrument Science and Opto-electronics \\ Engineering \\ Hefei University of Technology \\ Hefei, China \\ e-mail: 1527466604@qq.com \\ TaoJiayue \\ Institution of Instrument Science and Opto-electronics \\ Engineering \\ Hefei University of Technology \\ Hefei, China \\ e-mail:1437828452@qq.com
}

important way to improve the six-axis force measurement accuracy.

The air-floating six-axis force measurement platform based on the principles of air-floating force measurement may prevent inter-dimensional coupling and increasing precision significantly[7-9]. Principles of air-floating force measurement are illustrated in "Fig.1". In a nozzle and floating plate structure, the positive pressure or positive pressure component acting on the plate can be derived by measuring the flow parameters at a specific position.

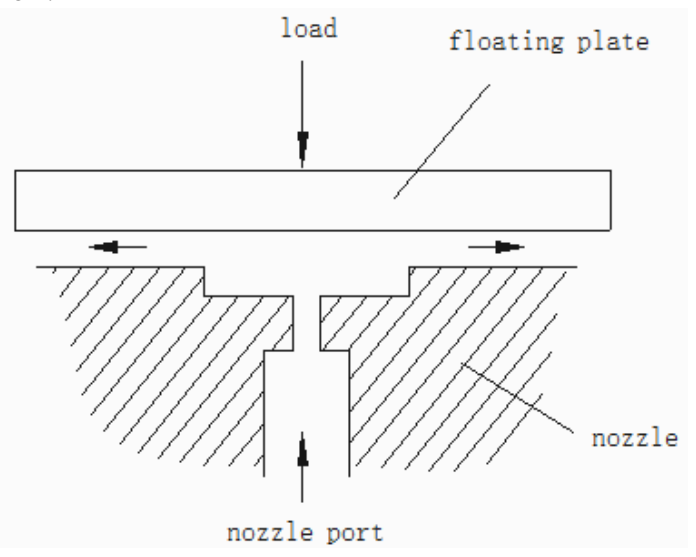

Figure 1. The diagram of flotation force measurement

II. DETERMINATION OF PARALLEL DEGREE TOLERANCE VALUE OF NOZZLE AND FLOATING PLATE

Structure of the air-floating six-axis force 
measurement platform is illustrated in "Fig.2". The rectangular hexahedron floating-plate is fully floating with the support of air-floating nozzles, and the nozzle end is parallel to its opposite floating plate surface.

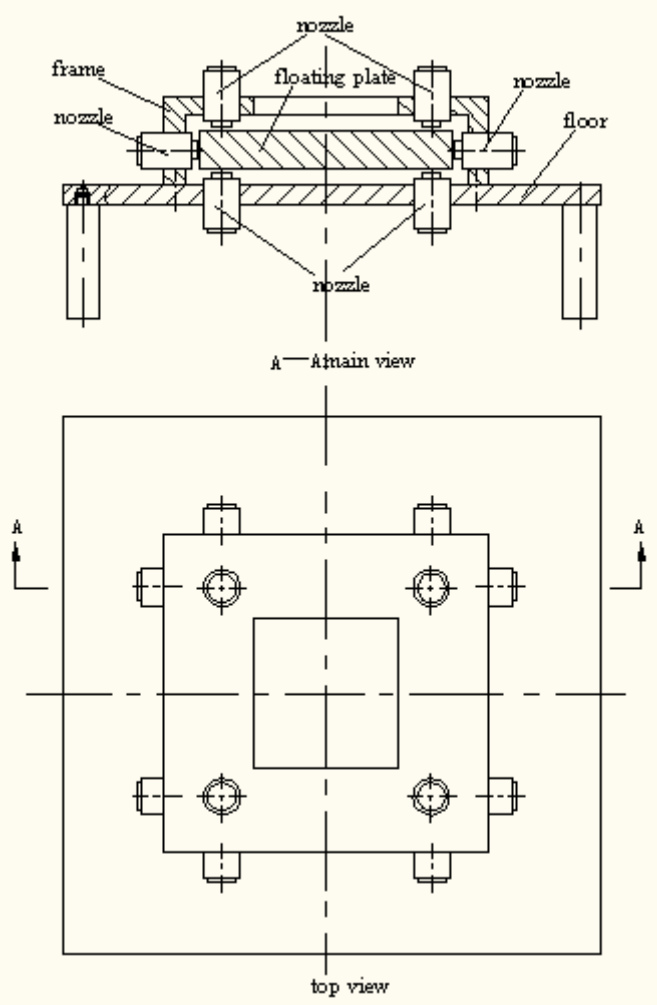

Figure 2. The separation nozzle structure design

The parallel degree of the nozzle and the floating plate must be strictly required to avoid the inter-dimensional coupling. Influence of the parallelism error of the nozzle and the floating plate on the measurement accuracy is the important basis for determining the parallel degree tolerance between the nozzle and the floating plate.

Several cases in which the nozzle end is not parallel to the floating-plate are illustrated in "Fig.3". "Fig.3(a)" shows that two surfaces of the floating-plate are parallel to each other while the nozzle's are not, where the position of floating-plate is right and the nozzle's is not; "Fig.3 (b)" shows that two surfaces of the floating-plate are parallel to each other as well as the two surfaces of the nozzle which are not parallel to the surfaces of the floating-plate. There the floating-plate's position is right but the nozzle's is not; "Fig. 3(c)" shows that two surfaces of the nozzle are parallel to each other while the two surfaces of the floating-plate are not, where the nozzle's position is right and the floating-plate's is not; "Fig. 3(d)" shows that two surfaces of the floating-plate are parallel to each other as well as the two surfaces of the nozzle which are not parallel to surfaces of the floating-plate. There the nozzle's position is right but the floating-plate's is not; "Fig. 3(e)" shows that two surfaces of the floating-plate are parallel to each other as well as the two surfaces of the nozzle which are not parallel to surfaces of the floatingplate. There the floating-plate's position is not right because it is not perpendicular to the side reference plane.

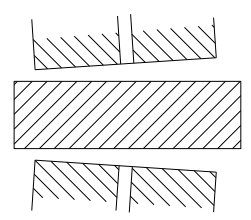

(a)

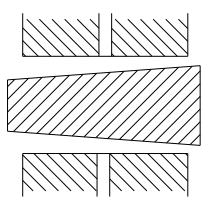

(c)

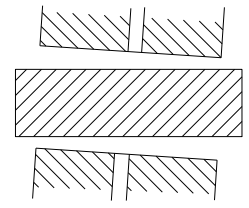

(b)

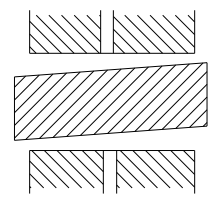

(d)

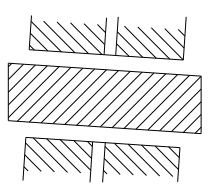

(e)
Figure 3. The diagram of unparallelism between nozzle end plane and the corresponding floating plate

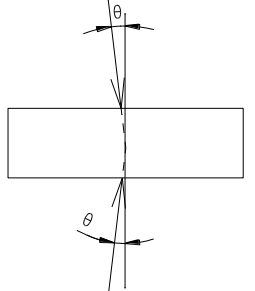

(a)

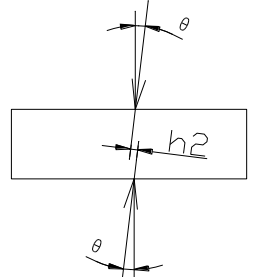

(b)
Figure 4. The force diagram of the unparallelism between nozzle end plane and the corresponding floating plate

The force analysis of the 4 cases described in "Fig.3" can be summarized as the two cases shown in "Fig.4". "Fig.4 (a)" describes the cases shown in "Fig.3 (a)" and (c), in which the forces of the floating plate produced by the two nozzles of a set intersect and between the force and floating plate surface normal is $\theta$; "Fig.4 (b)" describes the cases shown in "Fig.3 (b)" and (d), in which the forces of the floating plate produced by the two nozzles of a set are parallel to each other and the angle between the force and floating plate surface normal is $\theta$; When $\mathrm{h}_{2}=0$, "Fig.4 (b)" describes the case shown in "Fig.3 (e)".

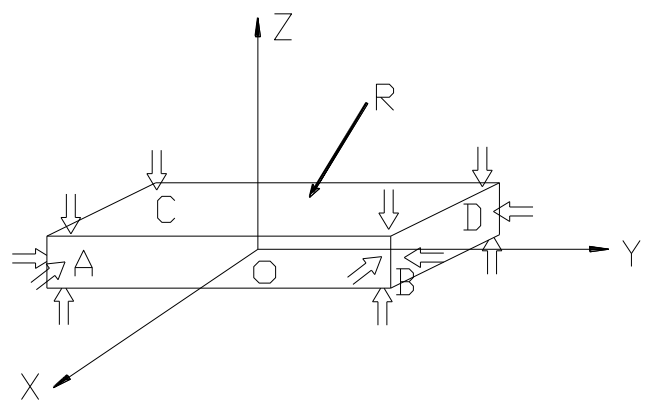

Figure 5. The diagram of physical model of the flotation six-dimensional force measurement

(1) As is shown in "Fig.5", if the nozzle in the direction of $\mathrm{Z}$ axis layout just as the case shown in "Fig.4(a)", we may assume the angle between the nozzle force acting on the floating plate and floating plate surface normal is $\theta$ and the angle between nozzle force's projection in the $\mathrm{X}-\mathrm{O}-$ 
$\mathrm{Y}$ coordinate plane and $\mathrm{X}$ axis, $\mathrm{Y}$ axis is $\alpha_{\mathrm{Z} 2}$ and $\beta_{\mathrm{Z} 2}$ respectively. Thus, we get the measuring errors of $F_{i}$ measured by the set of nozzles.

$$
\begin{aligned}
\Delta \mathrm{F}_{\mathrm{Zi}} & =(1-\cos \theta) \mathrm{F}_{\mathrm{i}} \\
\Delta \mathrm{F}_{\mathrm{Xi}} & =\mathrm{F}_{\mathrm{i}} \sin \theta \cos \alpha_{2} \\
\Delta \mathrm{F}_{\mathrm{Yi}} & =\mathrm{F}_{\mathrm{i}} \sin \theta \cos \beta_{2}
\end{aligned}
$$

Wherein $\Delta \mathrm{F}_{\mathrm{Zi}}$ is the measuring error of a pair of nozzles along the $\mathrm{Z}$ axis, which make actual measurement value small; $\Delta \mathrm{F}_{\mathrm{Xi}}$ is a component of $\mathrm{F}_{\mathrm{Zi}}$ along the $\mathrm{x}$ axis ,which will caused measuring error of the air-floating six-axis force measurement platform along $\mathrm{X}$ axis; $\Delta \mathrm{F}_{\mathrm{Yi}}$ is a component of $\mathrm{F}_{\mathrm{Zi}}$ along the $\mathrm{Y}$ axis, which will caused measuring error of the air-floating six-axis force measurement platform along $\mathrm{Y}$ axis.

Four pairs of nozzles are arranged symmetrically in the direction of $\mathrm{Z}$ axis. Due to each set of the nozzles and the tilt error with random uncertainty, $\Delta \mathrm{F}_{\mathrm{Xi}}$ and $\Delta \mathrm{F}_{\mathrm{Yi}}$ could overlap or offset as the tilt induced. In extreme cases, 4 sets of nozzles are inclined to the same direction, and the maximum error caused by the inclination of the 4 groups of nozzles in the direction of the $\mathrm{Z}$ axis is:

$$
\begin{gathered}
\Delta \mathrm{F}_{\mathrm{Z}}=4(1-\cos \theta) \mathrm{F}_{\mathrm{i}}=(1-\cos \theta) \mathrm{F}_{\mathrm{Z}} \\
\Delta \mathrm{F}_{\mathrm{XZm}}=4 \mathrm{~F}_{\mathrm{i}} \sin \theta \cos \alpha_{2}=\mathrm{F}_{\mathrm{Z}} \sin \theta \cos \alpha_{\mathrm{Z} 2} \\
\Delta \mathrm{F}_{\mathrm{YZm}}=4 \mathrm{~F}_{\mathrm{i}} \sin \theta \cos \beta_{2}=\mathrm{F}_{\mathrm{Z}} \sin \theta \cos \beta_{\mathrm{Z} 2}
\end{gathered}
$$

Wherein $\Delta \mathrm{F}_{\mathrm{Z}}$ is the maximum measuring error along the $\mathrm{Z}$ axis; $\Delta \mathrm{F}_{\mathrm{XZm}}$ is the maximum axial force measurement error caused by $F_{Z}$ along the $X$ axis; $\Delta F_{Y Z m}$ is the maximum axial force measurement error caused by $F_{Z}$ along the $\mathrm{Y}$ axis; $\mathrm{F}_{\mathrm{Z}}$ is the joint force of the 4 groups in the direction of the $\mathrm{Z}$ axis. For $\alpha_{\mathrm{Z} 2}+\beta_{\mathrm{Z} 2}=90^{\circ}, \Delta \mathrm{F}_{\mathrm{XZm}}$ and $\Delta \mathrm{F}_{\mathrm{YZm}}$ can not appear at the same time.

(2) As is shown in "Fig.5", if the nozzle in the $\mathrm{Z}$ axis layout just as the case shown in "Fig.4(b)", we may assume the angle between nozzle force's projection in the $\mathrm{X}-\mathrm{O}-\mathrm{y}$ coordinate plane and $\mathrm{X}$ axis, $\mathrm{Y}$ axis is $\alpha_{\mathrm{Z} 3}$ and $\beta_{\mathrm{Z} 3}$ respectively. Thus, we get the measuring errors produced by the set of nozzles.

$$
\begin{aligned}
\Delta \mathrm{F}_{\mathrm{Zi}} & =(\cos \theta-1) \mathrm{F}_{\mathrm{i}} \\
\Delta \mathrm{M}_{\mathrm{Xi}} & =\mathrm{F}_{\mathrm{Zi}} \mathrm{h}_{2} \cos \alpha_{\mathrm{Z} 3} \\
\Delta \mathrm{M}_{\mathrm{Yi}} & =\mathrm{F}_{\mathrm{Zi}} \mathrm{h}_{2} \cos \beta_{\mathrm{Z} 3}
\end{aligned}
$$

Wherein $\Delta \mathrm{F}_{\mathrm{Zi}}$ is the axial force measuring error of a pair of nozzle in the direction of $\mathrm{Z}$ axis, which make the actual measurement smaller along the $\mathrm{Z}$ axis; $\Delta \mathrm{M}_{\mathrm{Xi}}$ is the torque error caused by $\mathrm{F}_{\mathrm{Zi}}$ along the $\mathrm{X}$ axis; $\Delta \mathrm{M}_{\mathrm{Yi}}$ is the torque error caused by $\mathrm{F}_{\mathrm{Zi}}$ along the $\mathrm{Y}$ axis.

Four pairs of nozzles are arranged symmetrically in the direction of $\mathrm{Z}$ axis. Due to each set of the nozzles and the tilt error with random uncertainty, $\Delta \mathrm{F}_{\mathrm{Xi}}$ and $\Delta \mathrm{F}_{\mathrm{Yi}}$ could overlap or offset as the tilt induced. In extreme cases, 4 sets of nozzles are inclined to the same direction, and the maximum error caused by the inclination of the 4 groups of nozzles in the direction of the $\mathrm{Z}$ axis is:

$$
\begin{gathered}
\Delta \mathrm{F}_{\mathrm{Z}}=4(\cos \theta-1) \mathrm{F}_{\mathrm{i}}=(\cos \theta-1) \mathrm{F}_{\mathrm{Z}} \\
\Delta \mathrm{M}_{\mathrm{XZm}}=4 \mathrm{~F}_{\mathrm{Zi}} \mathrm{h}_{2} \cos \alpha_{3}=\mathrm{F}_{\mathrm{Z}} \mathrm{h}_{2} \cos \alpha_{\mathrm{Z} 3} \\
\Delta \mathrm{M}_{\mathrm{YZm}}=4 \mathrm{~F}_{\mathrm{Zi}} \mathrm{h}_{2} \cos \beta_{3}=\mathrm{F}_{\mathrm{Z}} \mathrm{h}_{2} \cos \beta_{\mathrm{Z} 3}
\end{gathered}
$$

Wherein $\Delta F_{Z}$ is the maximum measuring error caused by $\mathrm{F}_{\mathrm{Zi}}$ along the $\mathrm{Z}$ axis; $\Delta \mathrm{M}_{\mathrm{XZm}}$ is the maximum torque error caused by $F_{Z}$ along the $X$ axis; $\Delta M_{Y Z m}$ is the maximum torque error caused by $\mathrm{F}_{\mathrm{Z}}$ along the $\mathrm{Y}$ axis; $\mathrm{F}_{\mathrm{Z}}$ is the joint force of the 4 groups in the direction of the $\mathrm{Z}$ axis. For $\alpha_{\mathrm{Z} 3}+\beta_{\mathrm{Z} 3}=90^{\circ}, \Delta \mathrm{M}_{\mathrm{XZm}}$ and $\Delta \mathrm{M}_{\mathrm{YZm}}$ can not appear at the same time.

(3) As is shown in "Fig.5", if the nozzle in the Z axis layout just as the case shown in "Fig.4"(a)( Because of the symmetry of the nozzle layout in the direction of $\mathrm{X}$ axis and $Y$ axis, the nozzle is discussed only in the direction of the $\mathrm{X}$ axis.), we may assume the angle between nozzle forces acting on the floating plate and $X$ axis is $\theta$, and the angle between nozzle force's projection in the $\mathrm{Y}-\mathrm{O}-$ $\mathrm{Z}$ coordinate plane and $\mathrm{Y}$ axis, $\mathrm{Z}$ axis is $\beta_{\mathrm{X} 2}$ and $\gamma_{\mathrm{X} 2}$ respectively. Thus, we can decompose $F_{i}$ measured by the set of nozzles as follows:

$$
\begin{gathered}
\Delta \mathrm{F}_{\mathrm{Xi}}=(1-\cos \theta) \mathrm{F}_{\mathrm{i}} \\
\Delta \mathrm{F}_{\mathrm{Yi}}=\mathrm{F}_{\mathrm{i}} \sin \theta \cos \beta_{\mathrm{X} 2} \\
\Delta \mathrm{F}_{\mathrm{Zi}}=\mathrm{F}_{\mathrm{i}} \sin \theta \cos \gamma_{\mathrm{X} 2}
\end{gathered}
$$

Wherein $\Delta \mathrm{F}_{\mathrm{Xi}}$ is the measuring error of a pair of nozzles along the $\mathrm{X}$ axis, which make actual measurement value small; $\Delta \mathrm{F}_{\mathrm{Yi}}$ is a component of $\mathrm{F}_{\mathrm{Xi}}$ along the $\mathrm{Y}$ axis, which will caused measuring error of the air-floating six-axis force measurement platform along $\mathrm{Y}$ axis; $\Delta \mathrm{F}_{\mathrm{Zi}}$ is a component of $\mathrm{F}_{\mathrm{Xi}}$ along the $\mathrm{Z}$ axis, which will caused measuring error of the air-floating six-axis force measurement platform along $\mathrm{Z}$ axis.

Two pairs of nozzles are arranged symmetrically in the direction of $X$ axis. Due to each set of the nozzles and the tilt error with random uncertainty, $\Delta \mathrm{F}_{\mathrm{Yi}}$ and $\Delta \mathrm{F}_{\mathrm{Zi}}$ could overlap or offset as the tilt induced. In extreme cases, 2 sets of nozzles are inclined to the same direction, and the maximum error caused by the inclination of the 2 groups of nozzles in the direction of the $\mathrm{X}$ axis is:

$$
\begin{aligned}
\Delta \mathrm{F}_{\mathrm{X}} & =2(1-\cos \theta) \mathrm{F}_{\mathrm{i}}=(1-\cos \theta) \mathrm{F}_{\mathrm{X}} \\
\Delta \mathrm{F}_{\mathrm{YXm}} & =2 \mathrm{~F}_{\mathrm{i}} \sin \theta \cos \beta_{3}=\mathrm{F}_{\mathrm{X}} \sin \theta \cos \beta_{\mathrm{X} 2} \\
\Delta \mathrm{F}_{\mathrm{ZXm}} & =2 \mathrm{~F}_{\mathrm{i}} \sin \theta \cos \gamma_{3}=\mathrm{F}_{\mathrm{X}} \sin \theta \cos \gamma_{\mathrm{X} 3}
\end{aligned}
$$

Wherein $\Delta \mathrm{F}_{\mathrm{X}}$ is the maximum axial force measuring error along the $\mathrm{X}$ axis; $\Delta \mathrm{F}_{\mathrm{YXm}}$ is the maximum measuring error caused by $\mathrm{F}_{\mathrm{X}}$ along the $\mathrm{Y}$ axis; $\Delta \mathrm{F}_{\mathrm{ZXm}}$ is the maximum measuring error caused by $F_{X}$ along the $Z$ axis; $F_{X}$ is the joint force of the 4 groups in the direction of the $\mathrm{X}$ axis. For $\beta_{\mathrm{X} 2}+\gamma_{\mathrm{X} 2}=90^{\circ}, \Delta \mathrm{F}_{\mathrm{YXm}}$ and $\Delta \mathrm{F}_{\mathrm{ZXm}}$ can not appear at the same time. 
As is shown in "Fig.5", if the nozzle in the $\mathrm{X}$ axis layout just as the case shown in "Fig.4(b)", we may assume the angle between nozzle force's projection in the $\mathrm{Y}-\mathrm{O}-\mathrm{Z}$ coordinate plane and $\mathrm{Y}$ axis, $\mathrm{Z}$ axis is $\beta_{\mathrm{X} 3}$ and $\gamma_{\mathrm{X} 3}$ respectively. Thus, we get the measuring errors of $F_{i}$ measured by the set of nozzles.

$$
\begin{aligned}
\Delta \mathrm{F}_{\mathrm{Xi}} & =(1-\cos \theta) \mathrm{F}_{\mathrm{i}} \\
\Delta \mathrm{M}_{\mathrm{ZX}} & =\mathrm{F}_{\mathrm{Xi}} \mathrm{h}_{2} \cos \beta_{\mathrm{X} 3} \\
\Delta \mathrm{M}_{\mathrm{YX}} & =\mathrm{F}_{\mathrm{Xi}} \mathrm{h}_{2} \cos \gamma_{\mathrm{X} 3}
\end{aligned}
$$

Wherein $\mathrm{F}_{\mathrm{i}}$ is the axial force of a pair of nozzles; $\Delta \mathrm{F}_{\mathrm{Xi}}$ is the axial force measuring error caused by $F_{i}$ along the $X$ axis; $\Delta \mathrm{M}_{\mathrm{ZX}}$ is the torque error caused by $\mathrm{F}_{\mathrm{Xi}}$ along the $\mathrm{X}$ axis; $\Delta \mathrm{M}_{\mathrm{YX}}$ is the torque error caused by $\mathrm{F}_{\mathrm{Xi}}$ along the $\mathrm{Y}$ axis.

Two pairs of nozzles are arranged symmetrically in the direction of $X$ axis. Due to the random uncertainty of misalignment error of each pair of the nozzle, $\Delta \mathrm{M}_{\mathrm{ZX}}$ and $\Delta \mathrm{M}_{\mathrm{YX}}$ caused by dislocation could overlap or offset. In extreme cases, the 2 groups of nozzles are in the same dislocation direction, and the maximum error caused by the 2 groups of nozzles can be derived by the follow formula.

$$
\begin{gathered}
\Delta \mathrm{F}_{\mathrm{X}}=2(1-\cos \theta) \mathrm{F}_{\mathrm{i}}=(1-\cos \theta) \mathrm{F}_{\mathrm{X}} \\
\Delta \mathrm{M}_{\mathrm{ZXm}}=2 \mathrm{~F}_{\mathrm{Xi}} \mathrm{h}_{1} \cos \beta_{\mathrm{X} 1}=\mathrm{F}_{\mathrm{X}} \mathrm{h}_{1} \cos \beta_{\mathrm{X} 3} \\
\Delta \mathrm{M}_{\mathrm{YXm}}=2 \mathrm{~F}_{\mathrm{Xi}} \mathrm{h}_{1} \cos \gamma_{\mathrm{X} 1}=\mathrm{F}_{\mathrm{X}} \mathrm{h}_{1} \cos \gamma_{\mathrm{X} 3}
\end{gathered}
$$

Wherein $\Delta \mathrm{F}_{\mathrm{X}}$ is the maximum axial force measuring error along the $\mathrm{X}$ axis; $\Delta \mathrm{M}_{\mathrm{ZXm}}$ is the maximum torque error caused by $F_{X}$ along the $X$ axis; $\Delta M_{Y X m}$ is the maximum torque error caused by $F_{X}$ along the $Y$ axis; $F_{X}$ is the joint force of the 2 groups in the direction of the $\mathrm{X}$ axis. For $\beta_{\mathrm{X} 3}+\gamma_{\mathrm{X} 3}=90^{\circ}, \Delta \mathrm{M}_{\mathrm{ZXm}}$ and $\Delta \mathrm{M}_{\mathrm{YXm}}$ can not appear at the same time.

An parallelism error analysis is made between the nozzle and the floating plate. Assume the nozzle diameter is $\mathrm{D}$, and the parallelism between the nozzle and the floating plate surface is calculated by $0.003 \mathrm{~mm}$ throughout the assembly process, thus the maximum angle error between the nozzle surface and the surface of the floating plate is:

$$
\theta \approx \frac{0.003}{\mathrm{D}}
$$

\section{TEST DESIGN OF PARALLEL DEGREE BETWEEN THE NOZZLE AND THE FLOATING PLATE}

Since the nozzle is hidden between the frame and the table surface, the parallelism detection between the nozzle and the floating plate is difficult by conventional methods during the installation and debugging of the flotation sixdimensional force measurement platform. After practice, this paper puts forward a method of using indentation principle and equal-thickness gasket principle[10], solving the problem of parallelism detection which mentioned before.

\section{A. Method based on indentation comparison}

The method using indentation principle is illustrated in "Fig.6". As shown in "Fig.6", the composite paper pad is superimposed by the white paper and copying paper. In the test, as shown in "Fig.6 (a)", the composite paper pad is placed between the press block and the plane. Put a certain pressure on the press block, remove the press block, and then open the composite paper pad, we can test the indentation in the white paper. If the press block is parallel to the contact plane, the indentation will be complete, just as shown in "Fig.6 (b)". If the block is not parallel to the plane, as shown in "Fig.6 (c)", the indentation will not be complete. As shown in "Fig.6 (d)", the parallelism can be calculated by measuring the indentation length in "Fig. 6(c)". This method can be used as a preliminary test, after which we can use the method of comparison of equal thickness gaskets.

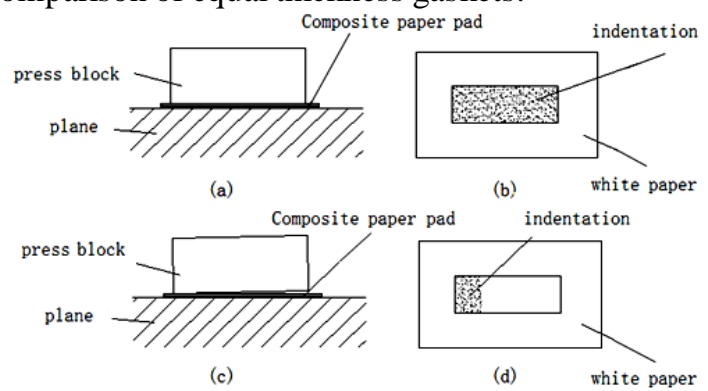

Figure 6. The diagram of indentation principle

Calibration experiment should be done before measuring the parallelism of the two planes by using the indentation measurement method[11]. In this paper, in the calibration experiment, block gauge's contact length is $45 \mathrm{~mm}$,which act as the press block; Inspection plate act as the plane and the composite pad of paper is superimposed by the white paper and copying paper. The principle of the experiment refer to "Fig. 6". As shown in "Fig. 6(c)", 0.02 $\mathrm{mm}$ feeler is put in one end of the press block between the press block and the plane, then we derived the indentation which is shown in "Fig.7". Here, "Fig.7(a)"corresponds to "Fig.6(b)" and "Fig.7(b)"corresponds to "Fig.6(d)". The indentation length measured in the experiment is about $15 \mathrm{~mm}$. Thus,we can get the parallelism error formula as follows.

$$
\delta=\frac{\mathrm{L}_{0}-\mathrm{L}}{\mathrm{L}_{0}} \times \frac{45}{45-15} \times 0.02=0.03 \times \frac{\mathrm{L}_{0}-\mathrm{L}}{\mathrm{L}_{0}} \mathrm{~mm}
$$

Where $\delta$ is the error value of the contact surface parallelism; $\mathrm{L}$ is the indentation length; L0 is the length of the contact surface. 


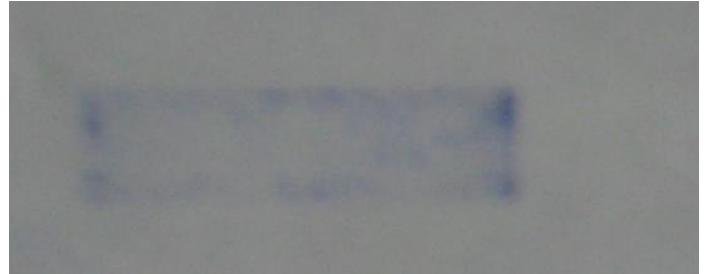

(a)

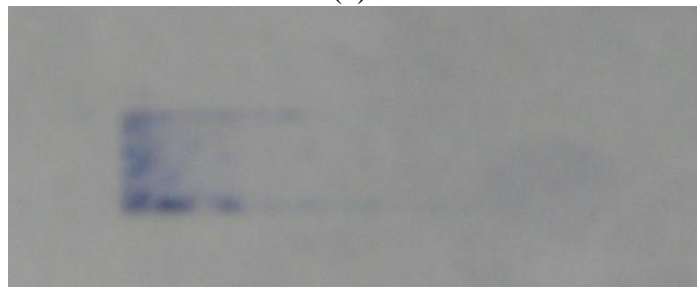

(b)

Figure 7. Calibration graphs obtained by indentation

When the parallelism error of the two plane is close to the plane parallel degree error in the process of calibration, accuracy of the indentation measurement is higher. It is difficult to get a shim which thickness is less than $0.01 \mathrm{~mm}$, so the paper uses the method of indentation measurement to test the parallelism to $0.01 \mathrm{~mm}$ before carrying on a fine tune with the method based on equal thickness gaskets.

\section{B. Method based on equal thickness gaskets}

The principle of the method based on equal thickness gaskets to measure the parallelism between the nozzle and floating plate is shown in "Fig.8". Put 4 rigid shim with equal-thickness but different color between the nozzle and the floating plate. The nozzle is supplied with a constant pressure on the floating plate. Then, the supply port of the nozzle is supplied with a constant- pressure gas and the compressed gas flow into the gap between the nozzle and the floating-plate through the throttle hole. If one of the shim is blown out, the gap in this direction is bigger than others, so the direction of the corresponding parallel error is determined.

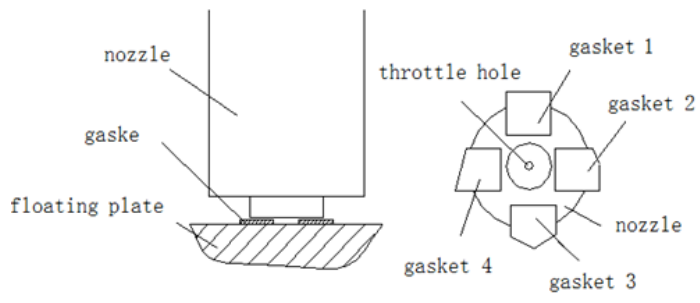

Figure 8 . The principle diagram based on the method of equalthickness gaskets measurement

The value of parallelism error is related to the air pressure. Before using the equal-thickness gaskets measuring method, we should determined the standard supplying air pressure based on the parallelism-tolerance value between the nozzle and the floating plate. In the experiment, parallelism between the nozzle and the floating plate is adjusted to $0.003 \mathrm{~mm}, 4$ pieces of rigid gasket is placed regularly between the nozzle and the floating plate, and the maximum gap is between two pieces of the gaskets. Press the nozzle on the floating plate with a constant pressure, then add air into the nozzle port.
Keep increasing the air pressure until one of the gaskets is blown out, so the supply pressure at that moment is the standard air pressure which used in the process of parallelism-error detection between the nozzle and the floating plate.

\section{Experimental program verification}

Firstly, the parallelism error between the nozzle and the floating plate is adjusted to $0.01 \mathrm{~mm}$ by using the method of indentation measurement. "Fig.9" shows the nozzle indentation derived from the experiment.

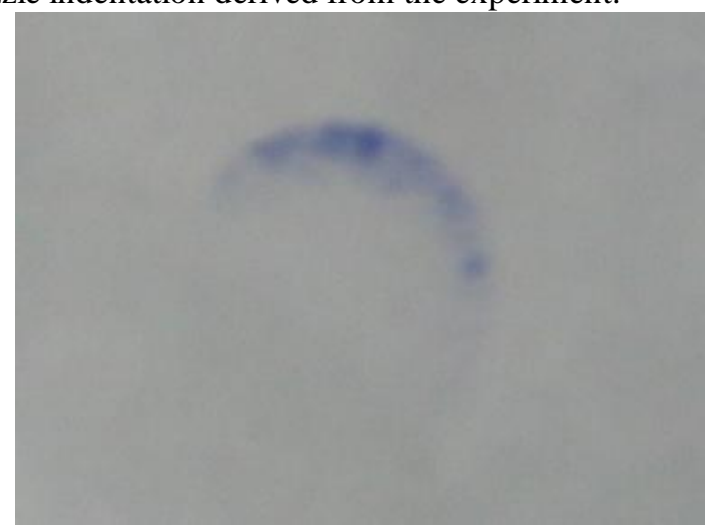

Figure 9. The indentation of nozzle

After the coarse adjustment, the parallel degree between the nozzle and the floating plate is adjusted with equal-thickness gaskets measuring method, which makes the parallelism error between the nozzle and the floating plate less than $0.003 \mathrm{~mm}$. The dimensions of the using gasket is $4 \times 4 \mathrm{~mm} 2$, which made by $0.02 \mathrm{~mm}$ standard feeler. The pressing force between the nozzle and the floating plate is $0.5 \mathrm{~kg}$ and the standard supply pressure of the nozzle is $0.2 \mathrm{MPa}$.

By using the above methods during the installation and debugging process of the air-floating six-axis force measurement platform, the parallelism error can be adjusted less than $0.003 \mathrm{~mm}$, which meets the design requirements. "Fig.10" is the air-floating six-axis force measurement platform.

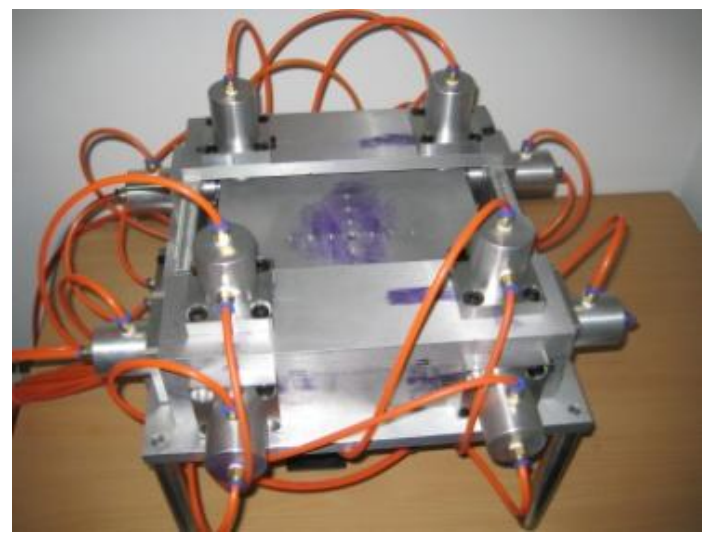

Figure 10. The air-floating six-axis force measurement platform

\section{CONCLUSIONS}

The method of using indentation principle and equalthickness gasket principle is a effective solution to solve 
the problems of parallelism detection between the nozzle and the floating plate. This method is easy to operate and its cost is low. It has certain reference value for solving the problems of the parallelism error measurement in narrow space.

\section{ACKNOWLEDGMENT}

This work was financially supported by Major scientific equipment development special projects:

Project supported by the National Natural Science Foundation of China (61072032);

Project supported by the Natural Science Foundation of Anhui province (1208085ME76);

Project supported by "the Fundamental Research Funds for the Central Universities" (2013HGBZ0167)

\section{REFERENCES}

[1] Li YJ, Wang GC, Zhang J, and Jia ZY, "Dynamic characteristics of piezoelectric six-dimensional heavy force/moment sensor for large-load robotic manipulator," Measurement, 45.Jun.2012,pp.1114-1125

[2] Asbeck A, Dastoor S, Parness A, Fullerton L, Esparza N, Soto $\mathrm{D}$, Heyneman B, and Cutkosky M, "Climbing rough vertical surfaces with hierarchical directional adhesion," Ieee Int Conf Robot, 2009,pp.4328-4333

[3] Shihua Q, Ying H, Xiaoyue H, Zhiguang S, Ping L, and Caixia L, "A dual-mode proximity sensor with integrated capacitive and temperature sensing units," Measurement Science and Technology, 26.Oct.2015,pp.105101 (105106 pp.)-105101 (105106 pp.),10.1088/0957-0233/26/10/105101.

[4] Wu B, and Cai P, "Decoupling Analysis of a Sliding Structure Six-axis Force/Torque Sensor," Meas Sci Rev, 13.2013,pp.187 193,10.2478/msr-2013-0028.

[5] Song AG, Wu J, Qin G, and Huang WY, "A novel selfdecoupled four degree-of-freedom wrist force/torque sensor," Measurement,40.Nov-Dec.2007,pp.883-891,10.1016/j.measu-rement.2006.11.018

[6] Zhao XD, and Pu JG, "Analysis of robot force sensor," Journal of Xingtai Polytechnic College, 2004, pp.21-23+39

[7] Huang B, Huang Y, and Wang HS, "Air-flotating multidimensional force sensor and multi-dimensional force measurement method," invention patent, CN101221077.

[8] Huang B, "Method on Force and position of the air-flotating measement," invention patent, CN101236112.

[9] Huang B, Yu XF, Huang Y, Huang HY, and Wang B, "Study on the static calibration method of flexible tactile sensor", Journal of the instrument, 31.2010, pp.2003-2009

[10] Huang B, Zhang WW, Ye H, Chen L, Wei X, and Song L, "A method for measuring the parallelism between the nozzle end face and the surface of the floating plate," invention patent, CN102829741A

[11] Huang B, "A flexible tactile sensor calibration method based on an air-bearing six-dimensional force measurement platform," Rev Sci Instrum,86.Jul.2015,pp,Artn 07500310.1063/1.4926 